\title{
Seasonal Variation in Host Susceptibility to Fusarium Canker in Young Almond Trees
}

\author{
Abigail J. Stack, Meera Madra, Thomas R. Gordon, and Richard M. Bostock ${ }^{\dagger}$ \\ Department of Plant Pathology, University of California, Davis, CA
}

\begin{abstract}
Loss of water that reduces the relative water content (RWC) of bark can occur during processing, cold storage, and planting of bare-root stone fruit trees. In California nurseries and newly planted orchards, this stress can predispose young almond trees (Prunus dulcis) to a canker disease caused primarily by Fusarium species. While reduced bark RWC contributes to disease development, anecdotal observations suggest a seasonal effect on host physiology may also influence disease severity. We evaluated the effect of season and the impact of drying and reduced RWC on susceptibility of almond branch segments excised from orchard trees (cv. Nonpareil) to Fusarium acuminatum, Fusarium avenaceum, Fusarium brachygibbosum, and Fusarium californicum sp. nov. With lesion size as the criterion, excised inoculated branch segments were most susceptible in spring, of intermediate susceptibility during winter dor-

moisture on lesion size was only apparent in the spring. These results affirm the importance of avoiding conditions that diminish moisture status in bare-root almond trees in Fusarium canker disease management, especially during transport and planting operations in the spring, a period of high physiological vulnerability. California nurseries apply fungicides to bare-root trees prior to cold storage to reduce "mold" growth. Of eight fungicides currently registered for use on almond trees, fludioxonil (Scholar), fluopyram/trifloxystrobin (Luna Sensation), and fluxapyroxad/pyraclostrobin (Merivon) were most inhibitory to in vitro mycelial growth of $F$. acuminatum, $F$. avenaceum, and $F$. brachygibbosum. However, our almond branch disease assay did not demonstrate preventive or curative fungicide action against infections by $F$. acuminatum or $F$. avenaceum.
\end{abstract} mancy, and least susceptible during summer and fall. Consistent with an earlier study, branches with RWC between 80 and $85 \%$ yielded lesions that were significantly larger than lesions from branches with bark that was above or below that range. However, the effect of reduced bark
Keywords: bark, Fusarium acuminatum, Fusarium avenaceum, Fusarium brachygibbosum, Fusarium californicum sp. nov., relative water content, water stress
Previous research identified a fungal canker disease affecting bare-root and newly planted fruit and nut trees within the family Rosaceae that implicated reduced bark moisture as a predisposing factor (Marek et al. 2013). Disease symptoms initially manifest as "mold" growth on the bark surface during storage in refrigerated facilities, with cankers appearing during cold storage or shortly after planting. In past outbreaks, the disease has caused losses of many tens of thousands of trees in California nurseries and newly planted orchards, resulting in millions of dollars of lost revenue to the industry.

Cold storage over several months and the shock of transplanting can cause drying of tissues and water stress in trees (Garriou et al. 2000). An initial study established that branch cuttings from coldstored bare-root almond trees are predisposed to opportunistic fungi when bark relative water content (RWC) falls below a certain

${ }^{\dagger}$ Corresponding author: R. M. Bostock; rmbostock@ucdavis.edu

During the course of this project, a group of morphologically similar isolates of a Fusarium sp. were obtained from diseased bare-root almond trees. These isolates are a newly described lineage nested within the 'tricinctum' complex, and comprise a new species, Fusarium californicum sp. nov.

Current address of A. J. Stack: Bayer Crop Science, 37437 State Highway 16, Woodland, CA 95695.

Funding: Research supported by grants from the California Fruit Tree, Nut Tree, and Grapevine Improvement Advisory Board administered by the California Department of Food and Agriculture.

*The $\boldsymbol{e}$-Xtra logo stands for "electronic extra" and indicates that one supplementary figure and three supplementary tables are published online.

The author(s) declare no conflict of interest.

Accepted for publication 2 October 2019.

(C) 2020 The American Phytopathological Society threshold. Fusarium acuminatum, Fusarium avenaceum, and species within the anamorphic genus Cylindrocarpon (i.e., teleomorphs Nectria ramulariae and Ilyonectria robusta) were identified as the principal causal agents (Marek et al. 2013). In addition to water stress, other factors can impact disease severity and canker development in perennial hosts, including seasonal effects on host physiology and development, and relative humidity (Agrios 2005; Kozlowski 1969). We investigated relative humidity previously and found it not to be a significant factor, although low humidity during storage would be expected to exacerbate water loss in bare-root stock (Marek et al. 2013). In addition, in many pathosystems, age of the plant can be a factor whereby young plants are often more susceptible to disease than mature plants (Agrios 2005; Develey-Rivière and Galiana 2007). This appears to be the case for the canker disease in the present study as the disease is generally observed in bare-root and newly planted trees (1st and 2nd leaf/year) and not in older or mature trees (beyond 3rd leaf/year).

Following the severe initial outbreak in 1997-98 and our identification of causal fungi, nurseries began spraying fungicides on bare-root trees immediately after digging and prior to transfer into refrigerated storage facilities. However, it remains to be established if this practice reduces disease incidence or severity. A complicating issue is that the Fusarium species of concern appear to be endophytic in almond [(Prunus dulcis (Mill.) Webb) (Marek et al. 2013). These asymptomatic, or cryptic, infections may originate in young trees during propagation and growth in field nurseries, although how trees become infected is unclear. Several fungicides were evaluated initially, and fludioxonil (Scholar) was found to be the most effective inhibitor in radial growth assays for the two principal causal agents, $F$. acuminatum and $F$. avenaceum (Marek and Bostock 2000). Since those initial tests, we identified additional pathogenic Fusarium species in almond (Stack et al. 2017), and new fungicides have been registered for use in California fruit and nut tree nurseries.

This study builds upon previous findings (Marek et al. 2013) and further examines bark water status in relation to canker development in almond that includes an assessment of the potential for 
seasonal differences in host susceptibility. Disease assays were performed every 3 months over a 2 -year period with excised branch segments that were subjected to varying degrees of drying and then inoculated with four Fusarium species. The specific objectives of this research were to further characterize the effect of bark RWC on susceptibility of excised almond branches to canker-forming Fusarium species, to determine if host susceptibility varies seasonally, and to evaluate a set of currently registered fungicides for their inhibition of these fungi. Portions of this research have been presented in abstract form (Seidle et al. 2015).

\section{Materials and Methods}

Disease assay. To determine the susceptibility of almond branches in relation to bark moisture status, we used the following disease assay. Almond branches (Prunus dulcis cv. Nonpareil) were collected from trees in an experimental orchard at the University of California Armstrong Research Farm in Solano County, CA. These trees were planted in 2012 as 3/4-inch bare-root stock and maintained for vigorous and healthy growth under standard nutritional and irrigation regimes for almonds in this region but were not treated with pesticides. For each collection during 2014-16, branches (1-2 cm diameter) were removed from almond trees that were 3 to 5 years old (i.e., 3rd- to 5th-leaf stage) through the course of this study, with one branch obtained from each of 10 trees. Branches were taken to the laboratory, and all leaves, nuts, and lateral branches were removed from the main stem with pruning shears. Branches were then cut into 15 -cm-long segments and surface-sterilized by submersion in $0.6 \%$ sodium hypochlorite in a plastic container for $5 \mathrm{~min}$ on an orbit shaker followed by two 3-min rinses in deionized water. Branch segments ( $n=29$ for each collection) were then blotted on paper towels to remove free moisture, placed into sterile $25 \times 200 \mathrm{~mm}$ glass test tubes, and capped with an autoclaved foam Identi-Plug (Jaece, North Tonawanda, NY).

For studies on the influence of bark RWC on host response to infection, branches were collected over 3 weeks to create three drying periods prior to inoculation: 14 days (week-1 collection), 7 days (week-2 collection), and 0 days (week-3 collection). Test tubes containing week-1 and week- 2 collected branch segments were placed in a $15^{\circ} \mathrm{C}$ incubator at ambient relative humidity $(\sim 35 \%)$. At the time of the week- 3 collected branch segments ( 0 days of drying), all branch segments representing the three drying regimes were inoculated as follows: each of 24 branch segments from each time point was punctured to the sapwood with an 18-gauge needle to create two infection courts, with one wound positioned $5 \mathrm{~cm}$ from each end of the branch segment. One wound was wrapped in Buddy-Tape (Riken USA Corp., Novi, MI) as the wounded control, while the other wound was inoculated with a colonized filter paper piece (approximately $4 \mathrm{~mm}^{2}$ ) from the surface of a PDA culture of the test Fusarium species. The wounds were then wrapped with Buddy-Tape. The following almond isolates of each Fusarium species were used in this study: F. acuminatum (isolates BL52, BL69, BL72), F. avenaceum (isolates BL27, BL45), F. brachygibbosum (isolate BL33), and the newly described Fusarium californicum sp. nov. (isolate BL24) (Lawrence et al. 2019). Five $\mathrm{ml}$ of sterile water were added to the test tube before replacing the inoculated branch segment into the tube, with the inoculated wound end closest to the water. Each fungal isolate was inoculated onto three branch segments for each drying time point. Therefore, for each fungal species at each sample point, the number of replicates was based on the number of isolates tested: nine (3 isolates) for $F$. acuminatum, six ( 2 isolates) for $F$. avenaceum, and three each (1 isolate each) for $F$. brachygibbosum and $F$. californicum sp. nov. For positive controls, three of the 24-branch segments at each drying time point were inoculated with Monilinia fructicola (isolate Mf13-81, aka MUK-1, [Lee and Bostock 2007]) using the filter paper method described above. The remaining five-branch segments were set aside for bark RWC measurements (Marek et al. 2013). Tube racks of inoculated branches were returned to the $15^{\circ} \mathrm{C}$ incubator for 14 days prior to determining canker sizes. To assess canker development in inoculated branches, bark was peeled away from the control and pathogen-inoculated wound sites to expose inner necrosis of the cambium and sapwood. Lesion lengths and widths surrounding each wound, approximating a rectangle, were recorded and used to calculate the necrotic area for each biological replicate at each desiccation level. Also, it was noted whether the lesion was visible on the bark surface prior to peeling, and pictures were taken of each branch segment to create a digital archive.

To confirm infections by the test isolates used in these experiments, pieces of necrotic bark from a lesion edge were cultured on Komada's medium (KOM) (Komada 1975) with four pieces of tissue per culture plate, and cultures allowed to grow for 1 week under fluorescent light at room temperature $\left(23^{\circ} \mathrm{C}\right)$. One isolate from each KOM plate was subcultured onto carnation leaf agar (CLA) (Leslie and Summerell 2006), grown for 2 weeks, and then microscopically examined for presence of characteristic macroconidia. All noninoculated control wounds similarly cultured on KOM were negative for the presence of Fusarium spp.

Determination of bark relative water content. Bark RWC was determined similar to the general method of Bier (Bier 1959) and according to that described by Marek et al. (2013). Note that in our earlier study we used the older but equivalent term "bark turgidity" instead of RWC. Ten 7-mm-diameter cork-borer discs were taken from each of the 15 branches set aside for RWC measurement. Each sample, a set of 10 discs consisting of the outer and inner bark tissue and adhering cambium cells external to the xylem, was immediately weighed, and the fresh weight (FW) was recorded. Each sample was placed in a 15-ml screw-cap Nunc conical centrifuge tube (Thermo Scientific, \#339650) with deionized water, and incubated in the dark overnight at $4^{\circ} \mathrm{C}$. Each sample of discs was collected by filtering with a sieve, and excess water was removed from the disc surfaces by gently patting them on a paper towel. They were immediately weighed to determine the wet weight (WW). Samples were then placed in an $80^{\circ} \mathrm{C}$ oven overnight. Samples were cooled to room temperature $\left(23^{\circ} \mathrm{C}\right)$ in a desiccator and then weighed to determine the dry weight (DW). The percentage RWC of each sample at each drying regime was determined from the equation: $[(\mathrm{FW}-\mathrm{DW}) /(\mathrm{WW}-$ DW) $] \times 100$.

The RWC in relation to susceptibility was evaluated four times per year, once per season, over a period of 2 years (2014-2016). To simplify the analysis and presentation, RWC values were compiled into categories representing four ranges: RWC $<75 \%, 75 \% \leq \mathrm{RWC}<$ $80 \%, 80 \% \leq \mathrm{RWC}<85 \%$, and RWC $\geq 85 \%$.

Statistical analyses of lesion data. Statistical analyses were performed using JMP Pro software version 14.0 or PC-SAS version 9.1 (SAS Institute, Cary, NC). An ANOVA was performed whereby a model was constructed with average lesion area as the dependent variable and with Fusarium species, season, drying period, and RWC range as independent variables. The residual errors from that model were found not to fit a normal distribution $(\mathrm{W}<0.95)$. The lesion area data were then log-transformed and the same independent variables were tested against the transformed data. The residual errors of this model were found to fit the normal distribution ( $\mathrm{W}=0.9898$ ). Data were analyzed using mixed models with log lesion area as the dependent variable, and isolate, season, and drying period as fixed effects. Replication, year, and all interaction terms were coded as random effects. The significance of random effects was evaluated with a $\chi^{2}$ test to compare residual log likelihood values obtained with and without the random term included in the model. Only random effects that improved the fit of the model were retained. The significance of mean differences was determined using Tukey's all-pairwise comparison test with correction for multiple comparisons. In addition, a separate mixed model analysis was performed for the positive controls (Monilinia-inoculated branches), with log lesion area as the dependent variable, year as a random effect, and season and drying time as fixed effects. Interaction terms were coded as random effects.

In vitro fungicide tests. Eight fungicides or fungicide mixtures labeled for use on almond in California were evaluated for their potential to inhibit the canker-forming Fusarium species in radial growth assays in water agar (WA) medium (5.5-cm-diameter plates). One isolate each of $F$. avenaceum (isolate BL25), $F$. acuminatum (isolate BL23), and F. brachygibbosum (isolate BL32) was used in these 
tests. The fungicides tested were azoxystrobin (Abound, Syngenta, Greensboro, NC, 22.9\% a.i.), azoxystrobin/difenoconazole (Quadris Top, Syngenta, 18.2\%/11.4\% a.i.), fludioxonil (Scholar, Syngenta, $50 \%$ a.i.), fluopyram/trifloxystrobin (Luna Sensation, Bayer CropScience, Leverkusen, Germany, 21.4\%/21.4\% a.i.), fluopyram/ tebuconazole (Luna Experience, Bayer CropScience, 17.6\%/17.6\% a.i.), fluxapyroxad/pyraclostrobin (Merivon, BASF, Ludwigshafen, Germany, 21.26\%/21.26\% a.i.), propiconazole (Tilt, Syngenta, $41.8 \%$ a.i.), and pyraclostrobin/boscalid (Pristine, BASF, $12.8 \%$ / $25.2 \%$ a.i.). Stock suspensions were prepared for each fungicide at $10,000 \mathrm{ppm}$ active ingredient (a.i.; based on the more abundant ingredient in the case of uneven product mixtures) that were added to $1.5 \%$ WA cooled to $50^{\circ} \mathrm{C}$ after autoclaving to create media at 0 (control), 1,5 , and $10 \mathrm{ppm}$ a.i. for each product.

A colonized filter paper piece $(\sim 4 \mathrm{~mm} \times 4 \mathrm{~mm})$ of each isolate to be used in the trial was placed on $1.5 \% \mathrm{WA}$ and allowed to grow at room temperature $\left(23^{\circ} \mathrm{C}\right)$ under light $\left(4100 \mathrm{~K}, 67.8 \mu \mathrm{mol} / \mathrm{s} \cdot \mathrm{m}^{2}\right)$ for 5 days. Seven-mm-diameter agar discs were then excised using a cork borer near the growing edge of the mycelium, and one disc was placed mycelium-side down onto each fungicide-amended or nonamended (control) WA plate.

Radial growth on three plates for each isolate at each fungicide concentration was determined after 5 days incubation under the conditions described above. The largest diameter was measured and recorded. Approximate $\mathrm{EC}_{50}$ values for growth inhibition for each fungicide were determined from plots of colony diameter versus $\log$ (fungicide concentration) using the nonlinear regression for dose-response feature within Graphpad Prism 7.0 (Graphpad Software, San Diego, CA). One-way ANOVA and the Dunnett's test for fungicide treatment effect relative to a corresponding control also were performed with the radial growth measurements using JMP Pro14.0, after assuring that the data fit a normal distribution $(\mathrm{W}=0.96)$.

In planta fungicide tests. The three fungicides with the strongest relative growth inhibition - Luna Sensation, Merivon, and Scholar were chosen for in planta tests with inoculated, excised almond branch segments. Two trials, one conducted in December 2015 (branch segments with approximate RWC 82\%) and the other in March 2016 (approximate RWC 91\%), assessed potential preventive and curative action of these fungicides. Almond branches (cv. Nonpareil) were collected from the same experimental orchard described above. For each trial, approximately 14 branches (1-2 cm diameter) were cut from almond trees, one branch per tree. Branches were transported to the lab, and all leaves, nuts, and lateral shoots from the main stem of the branch were removed with pruning shears. Branches were sectioned into $15-\mathrm{cm}$ segments that were surfacesterilized as described above. For each trial, 48 branch segments were blotted to remove excess moisture, placed into sterile $25 \times 200 \mathrm{~mm}$ glass test tubes, and capped with an autoclaved foam Identi-Plug.

Branch segments were used on the day of collection to establish two test formats. One format evaluated the preventive action of the fungicides to protect wounds against canker development prior to inoculation, and the other format evaluated curative action of the fungicide on established infections. Twenty-four of the 48 branch segments were used in the preventive fungicide treatment format as follows: six branch segments were submerged into $500 \mathrm{ml}$ of 10 ppm a.i. suspensions of Luna Sensation, Merivon, Scholar, or sterile water (control) for $1 \mathrm{~min}$. Excess treatment solution was allowed to drip off for $30 \mathrm{~s}$, and then branch segments were returned to their tubes. Branch segments were then placed in an incubator at $15^{\circ} \mathrm{C}$ for $48 \mathrm{~h}$ to allow the treatments to dry. After drying, branch segments were removed from the incubator and each was stabbed with an 18gauge needle $5 \mathrm{~cm}$ from both ends as described in the inoculation procedure above. One wound was wrapped in Buddy-Tape to serve as the wound control while the other was inoculated with a piece of colonized filter paper (approximately $3 \mathrm{~mm}^{2}$ ) and wrapped with Buddy-Tape. Three branch segments per fungicide treatment were inoculated with $F$. acuminatum (isolate BL23). The other three branch segments per fungicide treatment were inoculated with $F$. avenaceum (isolate BL25). After inoculation, each branch segment was returned to a test tube and $3 \mathrm{ml}$ sterile deionized water added to the tube with the inoculated wound end of the branch segment placed in the water without wetting the inoculation site, stoppered, and returned to the incubator at $15^{\circ} \mathrm{C}$ for 14 days prior to lesion measurement. To evaluate the preventive test, bark was peeled from around the wounded control and the inoculated sites, and lesions analyzed as before.

The remaining 24 branch segments in each trial were used to assess the curative action of the fungicides. These branch segments were inoculated on the same day as branch collection. Each was stabbed with a needle $5 \mathrm{~cm}$ from both ends as above. One wound was wrapped in Buddy-Tape to serve as the wounded control, while the other was inoculated with a piece of colonized filter paper and wrapped in BuddyTape. Twelve branch segments were inoculated with $F$. acuminatum (isolate BL23), and 12 branch segments were inoculated with $F$. avenaceum (isolate BL25). Three $\mathrm{ml}$ of water was added to the tube with the inoculated wound end of the branch segment placed into the water as described above. Branches were returned to their tubes and incubated at $15^{\circ} \mathrm{C}$ for 7 days to allow infections to establish. The Buddy-Tape was then removed from the branches just prior to fungicide treatment. Six branch segments, three inoculated with $F$. acuminatum and three inoculated with $F$. avenaceum, were submerged in $500 \mathrm{ml}$ of $10 \mathrm{ppm}$ a.i. of the fungicide suspensions or sterile water (control) by the procedure described above. Branch segments were returned to the incubator at $15^{\circ} \mathrm{C}$ for an additional 14 days before lesions were measured. Curative tests were evaluated in the same manner described above for the preventive tests.

One-way ANOVA and the Tukey-Kramer HSD means comparison test were performed on the net log lesion area data using JMP 14.0 to determine significance of the treatment effects in both preventive and curative formats.

\section{Results}

We evaluated almond branches collected in midmonth of October (fall), January (winter), April (spring), and July (summer) over a 2year period from fall, 2014, through summer, 2016. The source trees for branches were in a well-maintained experimental orchard, subject to the seasonal variations in local weather. We compared the host reaction to isolates of four Fusarium species pathogenic on almond, two identified in the previous study, $F$. avenaceum and $F$. acuminatum (Marek et al. 2013), and two discovered recently, F. brachygibbosum (Stack et al. 2017) and F. californicum sp. nov. (Lawrence et al. 2019). We evaluated the impact of drying and corresponding effects on bark RWC on the susceptibility of branch segments to infection by these Fusarium spp. and lesion development.

The full data set was analyzed using analysis of variance, with season, drying time, and isolate coded as fixed effects, and replication, year, and all interaction terms coded as random effects. Because no random terms were significant $(P \geq 0.1087)$, data were analyzed using a model with only fixed effects. The results showed the main effects of season, drying time, and isolate all to be significant $(P<$ 0.0001 in all cases). Lesion area was largest in spring inoculations in both years (Fig. 1), and smallest in fall (year 1) or summer inoculations (year 2). Averaged across seasons, drying period, and isolates, and with the caveat that a limited number of isolates, one-to-three per species, was evaluated, $F$. avenaceum and $F$. brachygibbosum were the most virulent in both years (Fig. 2). In general, differences in lesion sizes within each season among the four species tested were not significant, with largest lesions in spring (Table 1). However, F. brachygibbosum produced the larger lesions in summer, year 2, and $F$. acuminatum produced the smaller lesions in winter, year 1, and fall, year 2, relative to the other species within that season. Averaged across years, the largest lesions occurred on branches subjected to a 14-day drying period when inoculations were performed in spring, but in other seasons, the effect of drying period length on lesion size was not significant (Fig. 3). The average lesion size in spring branches exposed to 14 days of drying was 9.7 -fold larger than the corresponding nonstressed branch segments (0 days drying).

Bark relative water content and seasonal susceptibility. We examined the impact of RWC, including RWCs below $80 \%$, in relation 
to potential seasonal effects on host susceptibility. There was a seasonal effect on the initial bark RWCs (i.e., 0 days of drying prior to inoculation). Branches collected in spring (April) had the highest initial bark RWC, branches collected in winter (January) and summer
(July) an intermediate initial bark RWC, and branches collected in fall (October) had the lowest initial bark RWC (Table 2). The decline in RWC over the course of the drying period prior to inoculation $(0,7$, and 14 days of drying) and averaged over all seasons during the
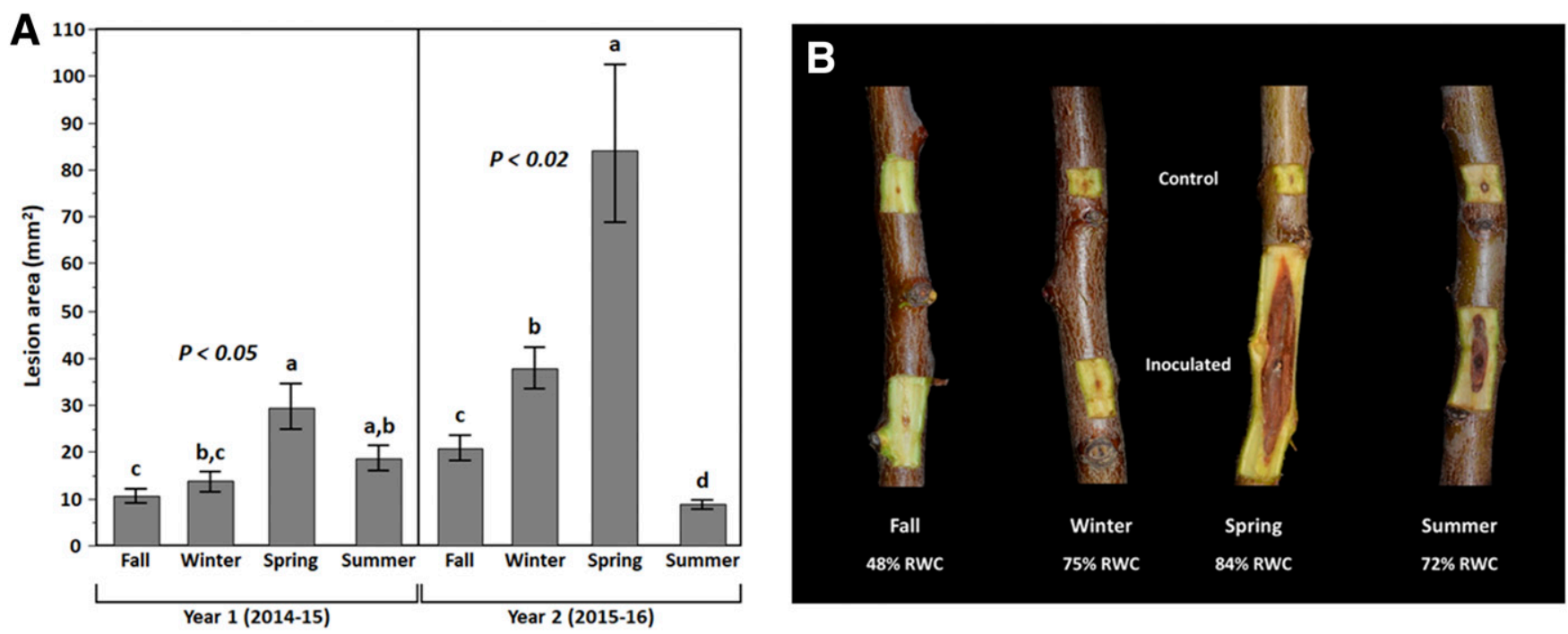

Fig. 1. The seasonal effect on susceptibility of almond branch segments to Fusarium canker development averaged across all relative water contents (RWCs). A, Lesion data combined for all isolates of the four Fusarium species and presented for each year (1 and 2) of the study. Means and SEM are indicated. Within year, significant differences are indicated by the lowercase letters atop each bar, $P<0.05$ (year 1) and $P<0.02$ (year 2) by means comparison of the log transformed lesion areas by the Tukey-Kramer HSD test. Values presented are the back-transformed (antilog) values. B, Lesion development in different seasons of year 1 in almond branch segments 2 weeks after inoculation with $F$. acuminatum (isolate BL69). Branches were subjected to a 14-day drying period prior to inoculation that resulted in a bark RWC at the time of inoculation as indicated. Outer bark was removed to show necrosis surrounding the noninoculated (control, upper) and inoculated (lower) sites on each branch segment.

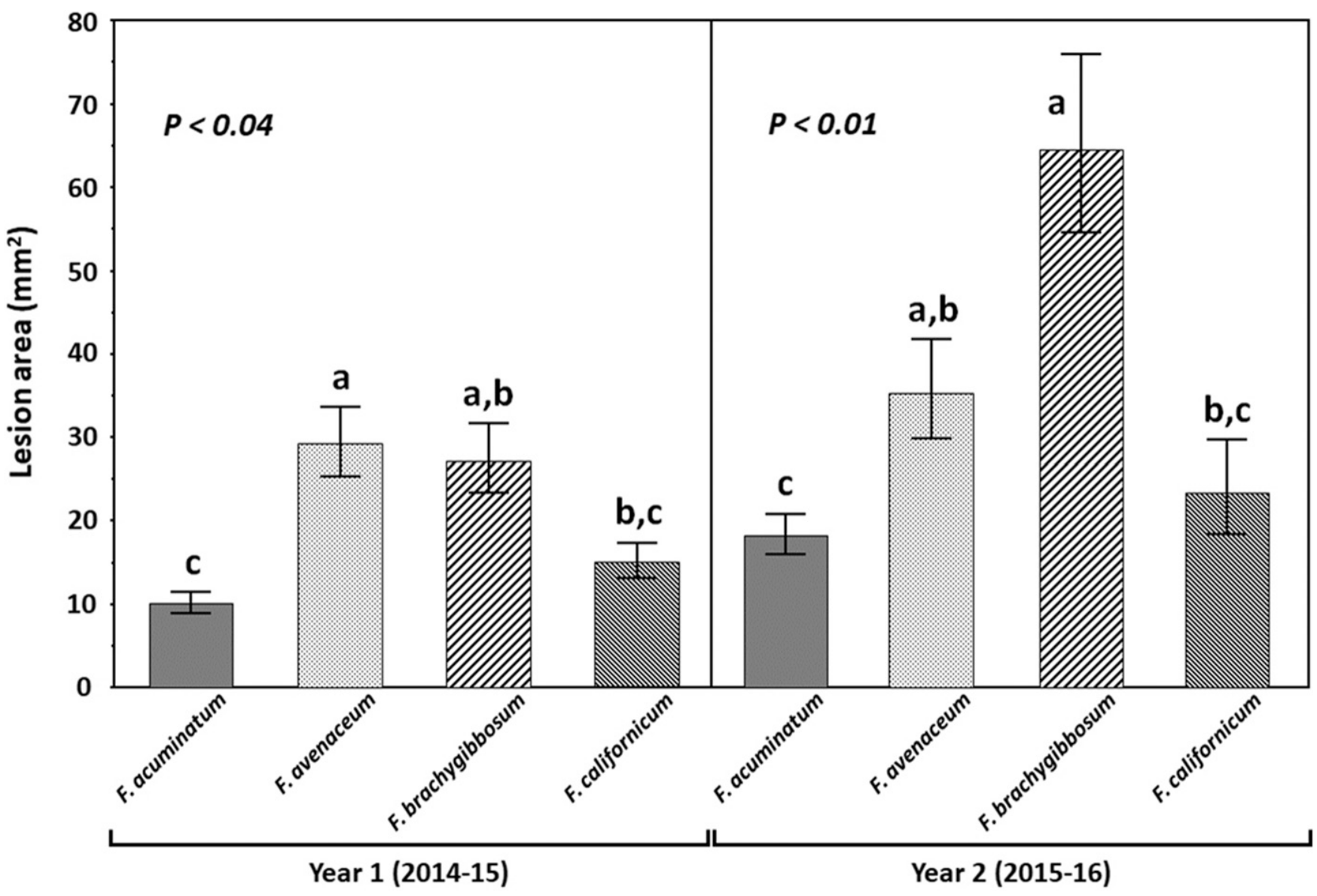

Fig. 2. Lesion sizes averaged over all seasons and relative water contents (RWCs) in almond branch segments for each of the Fusarium species. Means and SEM are indicated. Letters above each bar indicate significant differences by one-way ANOVA of the log transformed lesion areas and all pairwise means comparisons using the Tukey-Kramer HSD test $(P<0.02)$. Values presented are the back-transformed (antilog) values. 
2-year study is most precipitous during the second week of drying (i.e., between 7 and 14 days; Supplementary Fig. S1).

To determine the effect of RWC on host susceptibility, the data from all seasons for each of the 2 years (i.e., four sample sets for each year) were parsed into four RWC categories: RWC $<75 \%, 75 \% \leq$ RWC $<80 \%, 80 \% \leq \mathrm{RWC}<85 \%$, and RWC $\geq 85 \%$. The largest average lesion area occurs when bark RWC is between 80 and $85 \%$ for all of the Fusarium spp. tested (Fig. 4A), consistent with previous findings derived from a more limited data set and with one isolate of F. acuminatum as the pathogen (Marek et al. 2013). Although the initial RWCs of branch segments collected in the winter and summer (i.e., 0 days of drying; nonstressed) were within the optimum range for lesion development $(80 \% \leq \mathrm{RWC}<85 \%$; Table 2$)$, only small lesions developed in these branches. Spring branches were most responsive to predisposing drying periods, able to support the largest lesions following drying stress and inoculation. Within each drying period, lesions produced in inoculated spring branches always were significantly larger than lesions produced in inoculated branches collected in the other seasons (Supplementary Table S1).

Lesion development in almond branches inoculated with Monilinia fructicola. Branch segments inoculated with $M$. fructicola provided positive checks for lesion symptom expression throughout the study. Although there was considerable variation in $M$. fructicola lesion sizes, the effects of season, drying period, and RWC on Monilinia lesion development were different from those observed in branch segments inoculated with Fusarium species. Overall lesion areas in inoculated branch segments during year $1\left(9.2 \pm 5.7 \mathrm{~mm}^{2}\right)$ were significantly smaller than in year $2\left(53.0 \pm 7.1 \mathrm{~mm}^{2} ; \mathrm{F}=29.8 ; P<0.0001\right)$. However, the interaction of 'year' $x$ 'season', 'year' $x$ 'drying period', and 'year' $x$ 'season' $x$ 'drying period' were not significant (Wald $p$-values $=0.32,0.62$, and 0.44, respectively). Monilinia lesions, averaged across the different RWCs/drying periods, were significantly larger in branches assayed during summer than in branches assayed in winter $(P=0.017)$ and fall $(P=0.002)$, but not different in size than those in branches inoculated in spring (Table 3). The effect of drying period on lesion size was not significant in fall, winter, and spring, but the 14-day drying period significantly enhanced $M$. fructicola lesion development relative to the 0 - and 7-day drying periods in summer $(P=0.011$; data not shown). Across all seasons, the effect of bark RWC on lesion size was not significant (Table 4). However, withinseason comparisons revealed that the most severely stressed branches with RWC $<75 \%$ had larger lesions relative to those in branches in the other RWC categories in winter $(P \leq 0.005)$ and summer $(P=0.012$; data not shown).

In vitro fungicide tests. Eight fungicides were tested for inhibition of radial growth in cultures of $F$. acuminatum, $F$. avenaceum, and $F$. brachygibbosum (Supplementary Table S2). Luna Sensation and Merivon provided the strongest inhibition of $F$. acuminatum, with $\mathrm{EC}_{50}$ values less than $1 \mathrm{ppm}$. Scholar and Merivon most strongly inhibited growth of $F$. avenaceum, with both fungicides having $\mathrm{EC}_{50}$ values less than $1 \mathrm{ppm}$. Luna Sensation, Luna Experience, and Pristine also significantly $(P \leq 0.0001)$ inhibited $F$. avenaceum growth, comparable to Scholar and Merivon. Although Luna Experience and Pristine inhibited all three fungal species in culture, overall, they were not as active as Scholar, Merivon, or Luna Sensation. The $\mathrm{EC}_{50}$ values for the latter three fungicides against $F$. brachygibbosum were all less than $1 \mathrm{ppm}$. Quadris Top had an $\mathrm{EC}_{50}$ value of $0.25 \mathrm{ppm}$ for $F$. avenaceum, but never provided more than $50 \%$ growth inhibition at 5 and $10 \mathrm{ppm}$ for the other Fusarium

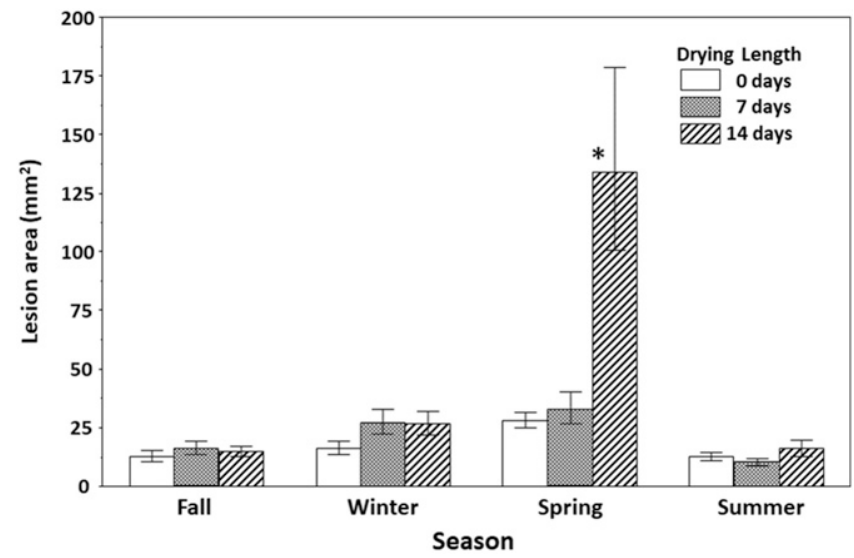

Fig. 3. The seasonal impact of drying almond branch segments prior to inoculation on Fusarium canker development. Data combined for years 1 and 2 are presented. Means and SEM are indicated ( $n=42$ for each value). Asterisk $\left(^{*}\right)$ indicates this value is significantly different from the 0 - and 7-day drying times for the spring sampling by Tukey's HSD of log lesion areas $(P<0.0001)$. Other within season values are not significantly different from each other. Values presented are the back-transformed (antilog) values.

Table 2. Seasonal effect on initial (i.e., 0 days drying) relative water content (RWC) of bark from almond branches on the day of collection from the orchard

\begin{tabular}{lc}
\hline Season & Initial RWC $(\boldsymbol{\%})^{\mathbf{z}}$ \\
\hline Fall & $76.0 \pm 0.4 \mathrm{c}$ \\
Winter & $83.4 \pm 0.2 \mathrm{~b}$ \\
Spring & $90.0 \pm 0.1 \mathrm{a}$ \\
Summer & $81.5 \pm 1.1 \mathrm{~b}$ \\
\hline
\end{tabular}

${ }^{\mathrm{z}}$ Means and SEM ( $\mathrm{n}=48$ for each season grouping, averaged over 2 years). Values followed by the same letter are not significantly different using a mixed model analysis of the arcsine square root transformed RWC data and all pairwise comparisons within Tukey's HSD $(P<0.0001)$.

Table 1. Mean lesion areas ( $\left.\pm \mathrm{SEM} ; \mathrm{mm}^{2}\right)$, pooled across drying times and isolates, in almond branch segments 2 weeks after inoculation with one of four $F u s a$ rium species in each of four seasons in each of 2 years

\begin{tabular}{lcccc}
\hline & Fall $^{\mathbf{z}}$ & Winter & Spring & Summer \\
\hline Year 1 (2014-15) & & & & \\
F. brachygibbosum & $18.4 \pm 5.1 \mathrm{a}$ & $13.1 \pm 3.8 \mathrm{a}$ & $62.2 \pm 13.1 \mathrm{a}$ & \\
F. avenaceum & $18.0 \pm 4.7 \mathrm{a}$ & $27.7 \pm 8.6 \mathrm{a}$ & $50.1 \pm 13.4 \mathrm{a}$ & \\
F. californicum sp. nov. & $11.9 \pm 2.4 \mathrm{a}$ & $18.4 \pm 7.8 \mathrm{a}$ & $14.6 \pm 2.9 \mathrm{a}$ & \\
F. acuminatum & $5.9 \pm 1.3 \mathrm{a}$ & $7.8 \pm 1.6 \mathrm{~b}$ & $20.0 \pm 6.0 \mathrm{a}$ & \\
Year 2 (2015-16) & & & & \\
F. brachygibbosum & $57.1 \pm 18.6 \mathrm{a}$ & $53.7 \pm 14.7 \mathrm{a}$ & $158.1 \pm 47.1 \mathrm{a}$ & \\
F. avenaceum & $22.1 \pm 25.5 \mathrm{a}$ & $50.1 \pm 11.4 \mathrm{a}$ & $125.2 \pm 42.4 \mathrm{a}$ & $35.6 \pm 9.2 \mathrm{a}$ \\
F. californicum sp. nov. & $35.2 \pm 6.6 \mathrm{a}$ & $44.9 \pm 14.1 \mathrm{a}$ & $57.4 \pm 40.2 \mathrm{a}$ & $11.2 \pm 2.3 \mathrm{~b}$ \\
F. acuminatum & $13.9 \pm 1.8 \mathrm{~b}$ & $26.0 \pm 4.3 \mathrm{a}$ & $58.2 \pm 19.5 \mathrm{a}$ & $5.9 \pm 0.9 \mathrm{~b}$ \\
\hline
\end{tabular}

${ }^{\mathrm{z}}$ Within column values (Means and SEM) within each year followed by the same letter are not significantly different by one-way ANOVA of the log transformed lesion areas and all pairwise comparisons within Tukey's HSD $(P \leq 0.05)$. Values presented are the back-transformed (antilog) values. Sample sizes for each species per season per year were as follows: F. brachygibbosum $(\mathrm{n}=9 ; 1$ isolate), F. avenaceum $(\mathrm{n}=18 ; 2$ isolates), F. californicum sp. nov. ( $\mathrm{n}=9 ; 1$ isolate), and $F$. acuminatum $(\mathrm{n}=27 ; 3$ isolates). 
species. Abound had little or no inhibitory activity for any of the fungi tested.

In planta fungicide tests. Because Scholar, Merivon, and Luna Sensation performed well in vitro, we attempted to test their preventive and curative action against $F$. acuminatum and $F$. avenaceum in excised branch segments. Although small lesions developed in the preventive format with all three fungicides, small lesions also developed in the water-treated inoculated controls that were not significantly different from the fungicide treatments (ANOVA, $\mathrm{F}=1.31$, $P=0.28$; Supplementary Table S3). This was also the case in the experiment to assess curative action of the fungicides (ANOVA, F = $1.24, P=0.30$ ).

\section{Discussion}

In this study, we show a strong seasonal effect on Fusarium canker development in branches from young almond trees grown under the environmental conditions of California's Sacramento Valley. Spring appears to be the period of greatest vulnerability, especially with respect to the impact of reduced RWC, as inferred by disease assays with excised branches (Figs. 1 and 3). Our results indicate an important interaction between physiological changes in young almond trees and their susceptibility to Fusarium canker development during the course of the year. Previously, we determined that preinoculation bark RWC between 80 and $85 \%$ predisposes almond branch segments to permit extensive cankers to develop following challenge with $F$. acuminatum (Marek et al. 2013). That study evaluated branches during late winter and found that RWC $\geq 85 \%$ greatly diminished canker/lesion development. In the present study, we affirm that there is an optimum range of bark RWC (i.e., 80 to $85 \%$ RWC) for this disease, whereby RWCs below and above that range are not conducive to canker development caused by multiple species of Fusarium, provided that other host physiological prerequisites, conducive for disease and developing during spring, are in place. The data suggest a developmental priming for susceptibility in spring branches that is strongly exacerbated by the stress of reduced bark RWC.

The cryptic nature of the Fusarium species associated with this canker disease led to the hypothesis that abiotic stress in the host permits contaminating or endophytic Fusarium species to transition to a parasitic phase to cause symptoms (Marek et al. 2013). We have used the overnight freezing induction technique (ONFIT) to activate infections and promote lesion development in surface-sterilized, healthyappearing budwood (Marek et al. 2013; Michailides et al. 2000). The emergence of these infections following freezing of surface-sterilized asymptomatic host material is consistent with a potential endophytic habit of the Fusarium species of concern in almond. Three of the causal species $-F$. avenaceum, $F$. acuminatum, and $F$. brachygibbosum were isolated from fungal growth that emerged from healthy-appearing

Table 3. Seasonal effect on lesion sizes in almond branch segments inoculated with Monilinia fructicola (isolate Mf13-81)

\begin{tabular}{lcc}
\hline & Log lesion area $\left(\mathbf{m m}^{2}\right)^{\mathbf{y}}$ & Lesion area $\left(\mathbf{m m}^{\mathbf{2}}\right)^{\mathbf{z}}$ \\
\hline Fall & $1.05 \pm 0.10 \mathrm{~b}$ & $11.2 \pm 2.6$ \\
Winter & $1.18 \pm 0.21 \mathrm{~b}$ & $15.1 \pm 7.6$ \\
Spring & $1.31 \pm 0.17 \mathrm{ab}$ & $20.4 \pm 8.2$ \\
Summer & $1.84 \pm 0.10 \mathrm{a}$ & $69.2 \pm 16.1$ \\
\hline
\end{tabular}

y Values are the means and SEM combined for years 1 and $2(n=18)$. Values followed by the same letter within the column are not significantly different by one-way ANOVA of the log transformed lesion areas and all pairwise comparisons within Tukey's HSD (summer versus fall, $P<0.0025$; summer versus winter, $P<0.017$ ).

${ }^{\mathrm{z}}$ Corresponding back-transformed (antilog) values are also presented.

Table 4. Relationship of bark relative water content (RWC) to lesion sizes in almond branch segments inoculated with Monilinia fructicola (isolate Mf1381) averaged across all seasons

\begin{tabular}{lcc}
\hline RWC category & Lesion area $\left(\mathbf{m m}^{2}\right)^{\mathbf{z}}$ & Sample size \\
\hline RWC $\geq 85 \%$ & $16.7 \pm 5.1$ & $\mathrm{n}=18$ \\
$80 \% \leq$ RWC $<85 \%$ & $16.1 \pm 7.1$ & $\mathrm{n}=18$ \\
$75 \% \leq$ RWC $<80 \%$ & $17.8 \pm 5.7$ & $\mathrm{n}=15$ \\
RWC $<75 \%$ & $43.6 \pm 17.8$ & $\mathrm{n}=21$ \\
\hline
\end{tabular}

$\mathrm{z}$ Values are the means and SEM. Sample sizes (n) for each RWC category are indicated. Values are not significantly different by one-way ANOVA of the $\log$ transformed lesion areas and all pairwise comparisons within Tukey's HSD $(P \leq 0.05)$. Back-transformed (antilog) values are presented.
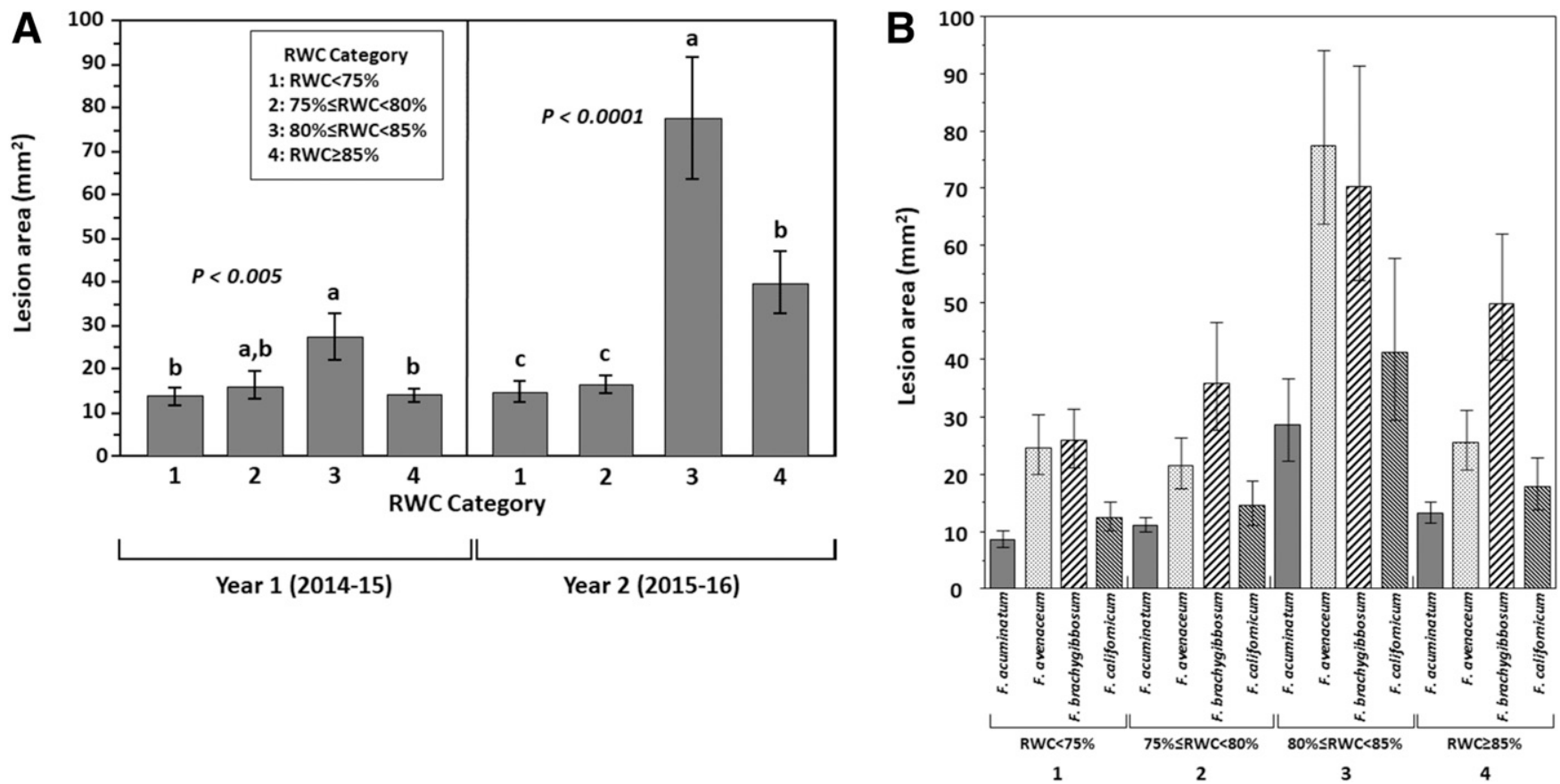

Fig. 4. The effect of relative water content (RWC, by category) on lesion areas in almond branch segments. A, Lesion data combined for the four Fusarium species and presented for each year of the study, and $\mathbf{B}$, with the lesion data parsed by individual Fusarium species within each RWC category but averaged across years. Means and SEM are indicated. In panel A, within year significant differences are indicated by the lowercase letters atop each bar, $P<0.005$ (year 1) and $P<0.0001$ (year 2) by the Tukey-Kramer HSD test of the log transformed lesion areas. Values presented are the back-transformed (antilog) values. 
stems of young almond trees following ONFIT. Thus far, we have isolated $F$. californicum sp. nov. only from symptomatic tissue, so it is possible that this new species is not an endophyte in almond, although we have no evidence to rule this out.

Predisposition in plant disease has been recognized and studied for over 125 years (Bostock et al. 2014; Boyer 1995; Sorauer et al. 1922). Factors such as temperature (MacDonald 1991; Traquair and White 1992), light intensity (Sutton et al. 1995), chilling (Zhao et al. 2012), frost damage (Young 1943), nutrient deficiency or excess (Dordas 2008), water stress (Bier 1959; Duniway 1977), salt stress (DiLeo et al. 2010), and transplant stress (Kozlowski and Pallardy 2002), among others, can all compromise plant disease resistance. Even short periods of mild stress can compromise plants to weak or opportunistic pathogens, host endophytes (Desprez-Loustau et al. 2006), and low levels of inoculum of virulent pathogens host plants would normally resist (Bostock et al. 2014). Indeed, the effects of water stress on the host plant have been shown to be a prominent factor in many Fusarium diseases (Bier 1959; Cook 1981), including stalk and root rots of grains caused by $F$. avenaceum (Papendick and Cook 1974).

There are many opportunities for stress events to occur in nursery production systems. A significant portion of fruit and nut trees in California are grown, dug, cold-stored as bare-root trees, and sold and distributed in a manner that can expose them to water, nutrient, and transplant stresses (Jacobs et al. 2009; Kozlowski and Pallardy 2002). Partial desiccation can occur in dormant trees during digging and removal from production fields, during sorting at the storage facility, or while in cold storage. Depending on weather conditions, bare-root almond trees are typically pulled from nursery production fields in late fall and early winter (November-December), and placed in cold-storage facilities until distribution and planting in growers' orchards throughout spring. We would anticipate stress severity and disease risk to increase when weather conditions hamper efficient processing of bare-root trees prior to cold storage, as would a longer interval in cold storage prior to planting. We recognize excised 1- to 2-year-old almond branches serve as experimental surrogates that only approximate the response of intact main stems of bare-root trees within a nursery production system. Nonetheless, given the resource constraints for our study, our experimental format allows precise and uniform incubation conditions to assess the effects of drying period on bark RWC, season, and different Fusarium species on almond branch susceptibility.

Some stresses, such as transplant stress, are unavoidable in the almond production system. The results presented here and in a prior study (Marek et al. 2013) indicate that efforts to mitigate loss of bark moisture in dormant trees and during initial establishment after planting should reduce the incidence and severity of Fusarium canker in almond and likely in other stone fruit trees. However, precise monitoring of bark water status of bare-root trees during storage and of newly planted trees in spring is challenging. RWC is a difficult measure to determine on-site at a nursery because calculating RWC involves wounding trees to obtain bark segments and a 2-day laboratory assay. Close monitoring of stem and leaf water potentials in the spring with a pressure bomb or portable pressure device in the field is possible, provided the relationship of water potential measurements to bark RWC is defined. Recently, we have examined this relationship and found that stem/leaf water potentials at best only approximate bark RWC (R. M. Bostock, unpublished).

Many fungi are well adapted to moist environments but not environments with excess or free water (Deacon 2006), i.e., the bark cannot be too dry or too wet. It is apparent that this also applies to the Fusarium species that attack almond. Our results also suggest that the parasitic habit of these Fusarium species is nuanced in the sense that very specific host physiological attributes must be in place for optimal lesion development. This is in contrast to M. fructicola, generally considered a necrotroph, which seems able to tolerate and cause cankers over the range of RWCs and seasonal differences examined in this study.

In our original study following severe disease outbreaks in the winters of 1997-98 and continuing into the next year, fludioxonil
(Scholar) was the strongest inhibitor against isolates of $F$. acuminatum, $F$. avenaceum, and Cylindrocarpon sp. collected at that time (Marek and Bostock 2000). Many nurseries now treat bare-root trees during fall and prior to cold storage with a combination of fungicides, including Merivon, and some refrigerated facilities are fogged with quarternary ammonium and a fungicide to 'sanitize' them. Although there are no efficacy data from controlled experiments to support this practice, anecdotal observations by nursery managers suggest that these practices reduce incidence of Fusarium canker and "molds" in bare-root stock. Since that last major outbreak, and since resistance to fludioxonil occurs in Fusarium species in other pathosystems (Gachango et al. 2011; Peters et al. 2008), an examination of other fungicides currently registered for use in almond was warranted. We tested eight fungicides representing several modes of action, including sterol biosynthesis inhibitors (DMIs), respiration inhibitors (SDHIs and QoIs), and one signal transduction inhibitor (PP). Three of the fungicides have single modes of action while the others are mixtures of two active ingredients, each of a different FRAC class (Ma and Michailides 2005).

The fungicides that strongly inhibited radial growth in culture among the three species tested $-F$. acuminatum, $F$. avenaceum, and $F$. brachygibbosum - were fludioxonil (Scholar), fluopyram/ trifloxystrobin (Luna Sensation), and fluxapyroxad/pyraclostrobin (Merivon), although these fungicides did not perform uniformly against these species. Scholar strongly inhibited $F$. avenaceum and $F$. brachygibbosum, but only weakly inhibited $F$. acuminatum. Merivon strongly inhibited $F$. acuminatum and $F$. avenaceum but was less effective against $F$. brachygibbosum. The variation in fungicide sensitivities among the complex of Fusarium species capable of causing cankers, even within our limited assessment, reveals a potential pitfall in the use of any one fungicide to attempt to manage the disease. Unfortunately, the in planta tests did not resolve whether these fungicides have any preventive or curative action in our assay format since the water-treated/inoculated controls produced small lesions similar in size to those in the fungicide treated/inoculated branches. The apparent effect of water to diminish lesion development could be due to restoration of bark RWC at the wound site into a range that was not conducive for infection. Additional work on this aspect is needed to devise a treatment and inoculation format that includes a predisposing drying period to overcome this ambiguity.

Other factors may contribute to Fusarium canker disease incidence and severity. Chemical defoliants, such as chelated copper or chelated zinc sprays, are widely used in California nurseries prior to digging and cold-storing bare-root trees. Defoliants can cause nutrient depletion (Guak et al. 2001), but whether the use of defoliants plays a role in this disease is unknown. Also unresolved is how trees become infected in the field or during processing and cold storage. In a companion study, we have found that Fusarium isolates obtained from diseased trees are associated with the same clonal lineage as isolates obtained throughout the production system, including soil and wheat stubble in production fields as well as on surfaces in coldstorage facilities (Seidle 2016). Small wounds and injuries incurred during handling and field operations are likely avenues for infection. We surmise that infections also could occur through roots, although we have no experimental evidence to support this.

Almonds are produced in California on over 530,000 hectares and are the third most valued agricultural commodity in the state, with a farm gate value of over $\$ 5.6$ billion US (CDFA 2019). Acreage has increased by about 50\% since 2010 and continues to increase (USDA/NASS 2019). In light of the demand for healthy planting stock, California fruit and nut tree nurseries will benefit from continuing review of practices that may exacerbate or mitigate stresses in propagation systems. Container propagation may help reduce contamination by Fusarium and Cylindrocarpon species associated with bare-root propagation and storage, and thus provide cleaner and healthier stock. Container propagation has increased considerably in California nurseries, recently coming to dominate production at some nurseries. Cultural practices such as selecting rotation crops alternative to the commonly used wheat in nursery tree production fields, sanitizing processing equipment and storage facilities, and 
refining water management to keep trees hydrated in production fields prior to digging and during cold storage are also considerations for further investigation to reduce disease incidence and severity.

\section{Acknowledgments}

We thank S. Kirkpatrick for her advice and support in maintaining and manipulating the Fusarium isolates used in this study, D. P. Lawrence for characterizing the Fusarium californicum sp. nov. used in portions of this study, J. E. Adaskaveg and D. Thompson for use of trees in the experimental orchard, and T. Brenes-Arguedas for statistical advice. We also thank staff at Sierra Gold Nursery (Yuba City, CA), The Burchell Nursery (Oakdale, CA), and Dave Wilson Nursery (Hickman, CA) for their cooperation. This work is part of a thesis submitted in partial fulfillment for completion of the M.S. degree by A. J. Stack (neé Seidle) (Seidle 2016).

\section{Literature Cited}

Agrios, G. N. 2005. Chapter Six - How plants defend themselves against pathogens. Pages 207-248 in: Plant Pathology, 5th ed. Academic Press, San Diego.

Bier, J. E. 1959. The relation of bark moisture to the development of canker diseases caused by native, facultative parasites. 2. Fusarium canker on black cottonwood. Can. J. Bot. 37:781-788.

Bostock, R. M., Pye, M. F., and Roubtsova, T. V. 2014. Predisposition in plant disease: Exploiting the nexus in abiotic and biotic stress perception and response. Annu. Rev. Phytopathol. 52:517-549.

Boyer, J. S. 1995. Biochemical and biophysical aspects of water deficits and the predisposition to disease. Annu. Rev. Phytopathol. 33:251-274.

CDFA. 2019. Pages 1-118 in: California Agricultural Statistics Review 20172018. California Department of Food and Agriculture, Sacramento, CA.

Cook, R. 1981. Pages 236-244 in: Fusarium: Diseases, Biology, and Taxonomy. Pennsylvania State University Press, University Park, PA.

Deacon, J. 2006. Fungal Biology. Blackwell Publishing, Malden, MA.

Desprez-Loustau, M. L., Marccais, B., Nageleisen, L. M., Piou, D., and Vannini, A. 2006. Interactive effects of drought and pathogens in forest trees. Ann. For. Sci. 63:597-612

Develey-Rivière, M. P., and Galiana, E. 2007. Resistance to pathogens and host developmental stage: A multifaceted relationship within the plant kingdom. New Phytol. 175:405-416.

DiLeo, M. V., Pye, M. F., Roubtsova, T. V., Duniway, J. M., MacDonald, J. D., Rizzo, D. M., and Bostock, R. M. 2010. Abscisic acid in salt stress predisposition to Phytophthora root and crown rot in tomato and chrysanthemum. Phytopathology 100:871-879

Dordas, C. 2008. Role of nutrients in controlling plant diseases in sustainable agriculture. A review. Agron. Sustain. Dev. 28:33-46.

Duniway, J. M. 1977. Predisposing effect of water stress on severity of Phytophthora root-rot in safflower. Phytopathology 67:884-889.

Gachango, E., Kirk, W. W., Hanson, L. E., Rojas, J. A., Tumbalam, P., and Shetty, K. 2011. First report of in vitro fludioxonil-resistant isolates of Fusarium spp. causing potato dry rot in Michigan. Plant Dis. 95:228.

Garriou, D., Girard, S., Guehl, J.-M., and Généré, B. 2000. Effect of desiccation during cold storage on planting stock quality and field performance in forest species. Ann. For. Sci. 57:101-111.

Guak, S., Cheng, L., and Fuchigami, L. H. 2001. Foliar urea pretreatment tempers inefficient $\mathrm{N}$ recovery resulting from copper chelate (CuEDTA) defoliation of apple nursery plants. J. Hortic. Sci. Biotechnol. 76:35-39.

Jacobs, D. F., Salifu, K. F., and Davis, A. S. 2009. Drought susceptibility and recovery of transplanted Quercus rubra seedlings in relation to root system morphology. Ann. For. Sci. 66:504.
Komada, H. 1975. Development of a selective medium for quantitative isolation of Fusarium oxysporum from natural soil. Rev. Plant Prot. Res. 8:114-125.

Kozlowski, T. T. 1969. Tree physiology and forest pests. J. For. 67:118-123.

Kozlowski, T. T., and Pallardy, S. G. 2002. Acclimation and adaptive responses of woody plants to environmental stresses. Bot. Rev. 68:270-334.

Lawrence, D. P., Stack, A. J., Gordon, T. R., and Bostock, R. M. 2019. Fusarium californicum D.P. Lawr, A.J. Stack, T.R. Gordon \& R.M. Bostock, sp. nov. In: Mycobank Database.

Lee, M-H., and Bostock, R. M. 2007. Fruit exocarp phenols in relation to quiescence and development of Monilinia fructicola infections in Prunus spp.: A role for cellular redox? Phytopathology 97:269-277.

Leslie, J. F., and Summerell, B. A. 2006. The Fusarium Laboratory Manual Blackwell, Oxford.

Ma, Z. H., and Michailides, T. J. 2005. Advances in understanding molecular mechanisms of fungicide resistance and molecular detection of resistant genotypes in phytopathogenic fungi. Crop Prot. 24:853-863.

MacDonald, J. D. 1991. Heat-stress enhances Phytophthora root rot severity in container-grown chrysanthemums. J. Am. Soc. Hortic. Sci. 116:36-41.

Marek, S. M., and Bostock, R. M. 2000. Etiology of cold storage canker of fruit and nut trees in California. Phytopathology 90:S49.

Marek, S. M., Yaghmour, M. A., and Bostock, R. M. 2013. Fusarium spp. Cylindrocarpon spp., and environmental stress in the etiology of a canker disease of cold-stored fruit and nut tree seedlings in California. Plant Dis. 97: 259-270.

Michailides, T. J., Morgan, D. P., and Felts, D. 2000. Detection and significance of symptomless latent infection of Monilinia fructicola in California stone fruits. Phytopathology 90:S53.

Papendick, R., and Cook, R. J. 1974. Plant water stress and development of Fusarium foot rot in wheat subjected to different cultural practices. Phytopathology 64: 358-363.

Peters, R. D., Platt, H. W., Drake, K. A., Coffin, R. H., Moorehead, S., Clark, M. M. Al-Mughrabi, K. I., and Howard, R. J. 2008. First report of fludioxonilresistant isolates of Fusarium spp. causing potato seed-piece decay. Plant Dis. $92: 172$

Seidle, A. J. 2016. Etiology, Epidemiology, and Management of Fusarium spp. Causing Cryptic Cankers in Cold-Stored, Bare-Root Propagated Almond Trees in California Nurseries. Master's Thesis. University of California, Davis, CA.

Seidle, A. J., Gordon, T. R., and Bostock, R. M. 2015. Etiology and management of Fusarium spp. causing cryptic cankers in cold-stored, bare-root propagated almond seedlings. Phytopathology 105:S4.125.

Sorauer, P., Lindau, G., Reh, L., and Dorrance, F. 1922. Manual of Plant Diseases Record Press, Wilkes-Barre, PA.

Stack, A. J., Yaghmour, M. A., Kirkpatrick, S. C., Gordon, T. R., and Bostock, R. M. 2017. First report of Fusarium brachygibbosum causing cankers in cold-stored, bare-root propagated almond trees in California. Plant Dis. 101: 390

Sutton, J. C., He, B., and Hopkin, A. A. 1995. Low-light intensity predisposes black spruce seedlings to infection by Botrytis cinerea. Can. J. Plant Pathol. $17: 13-18$

Traquair, J. A., and White, G. P. 1992. Cylindrocarpon rot of fruit trees in cold storage. Can. J. Plant Pathol. 14:310-314.

USDA/NASS. 2019. 2019 California Almond Forecast P. R. O. USDA/NASS, ed.United States Department of Agriculture, Sacramento, CA.

Young, G. Y. 1943. Root rots in storage of deciduous nursery stock and their control. Phytopathology 33:656-665.

Zhao, J., Li, S., Jiang, T., Liu, S., Zhang, W., Jian, G., and Qi, F. 2012. Chilling stress: The key predisposing factor for causing Alternaria alternata infection and leading to cotton (Gossypium hirsutum L.) leaf senescence. PLoS One 7: e36126. 